\title{
Transvaginal endoscopy: new technique evaluating female infertility. Three Mediterranean countries' experiences
}

Received: 13 May 2005/ Accepted: 29 July 2005/Published online: 8 September 2005

(c) Springer-Verlag Berlin / Heidelberg 2005

\begin{abstract}
Seventy-eight women from five different gynaecology departments, with infertility problems, were investigated to rule out mechanical factors by the new technique of transvaginal endoscopy (TVE). Tuboovarian structures were visualised in $70 \%$ to $100 \%$ of the cases, diagnosed pelvic endometriosis ranged from $9 \%$ to $20 \%$, and the overall frequency of adhesions was $20 \%$. In $7-10 \%$ of the cases $\mathrm{CO}_{2}$ laparoscopy was performed to verify the diagnosis made by TVE. The overall number of patients who avoided having to have $\mathrm{CO}_{2}$ laparoscopy, by undergoing TVE, was $41 / 78$ $(51 \%)$. The learning experience of TVE from different departments in three Mediterranean countries demonstrates accurate results, a low cost procedure, very good acceptance by the patients, and minimal complication risks depending on the surgeon's experience and the selection of the patients.
\end{abstract}

Keywords Transvaginal endoscopy $\cdot$ Female infertility investigation · Fertiloscopy

\footnotetext{
V. Tanos $(\square) \cdot$ D. Ioannou

P.O.B. 25441, Nicosia, 1309 Cyprus

E-mail: tanosV@spidernet.com.cy

Tel.: + 357-22-673340

Fax: + 357-22-673305

G. Bigatti $\cdot$ M. Rosales

Osp. S. Giuseppe, Milan, Italy

B. Magro

M.AT.R.I.S, Milan, Italy

L. Gianaroli

S.I.S.M.E.R., Bologna, Italy
}

Department of Gynaecology, Evagelistria Medical Centre,

M. Paschopoulos · F. Avgoustatos · D. E. Lolis

Hysteroscopy Unit, Department of Obstetrics and Gynaecology, Medical School of Ioannina, Ioannina, Greece

\section{Introduction}

Transvaginal endoscopy (TVE) has recently been introduced as a useful method for the diagnosis of infertility in women [1]. By insertion of a $3.5 \mathrm{~mm}$ diameter telescope through the posterior vaginal fornix, the fallopian tubes and the adnexae can easily be visualised and further investigated [2]. This method has been proposed for infertile women with low risk of pelvic abnormality, a rather normal gynecological history and normal sonographic appearance of the pelvis.

The traditional investigation of an infertile woman without suspicious history of pelvic adhesions or endometriosis is by hysterosalpingography (HSG). In patients with normal HSG results, induction of ovulation and artificial insemination with the husband's sperm is usually proposed for 4-6 cycles. If no pregnancy is achieved, then laparoscopy and hysteroscopy follow. The development of small-diameter telescopes has promoted pain-free hysteroscopy as an office procedure and recommended its application in every infertile woman prior to any infertility treatment [3].

The application of TVE as a substitute for standard diagnostic laparoscopy has encouraged gynaecologists to consider changes in their recommendations for infertile women with no obvious pelvic abnormalities [4]. By the application of office hysteroscopy and TVE, the mechanical factor within the uterine cavity, the ostia, and the proximal and distal part of the tubes can be eliminated, and no infertility treatments are given without complete diagnosis [5].

TVE can verify pelvic micro- and filmy adhesions and foci of endometriosis, which are not visible with standard laparoscopy [6]. Also, the small-diameter telescope can be inserted within the fibria (fibrioscopy) and propagated to the endosalpinx (infundibulum), enabling evaluation of the distal part of the salpinx. The diagnostic advantages of TVE over traditional laparoscopy, and which patients have an indication for TVE, are still 
under evaluation, and more studies are needed to draw final conclusions [4].

The aim of our study was to evaluate and compare the performance, diagnostic potential and the results of TVE at the initial learning period of five gynaecology groups in three different countries.

\section{Patients and methods}

\section{Patients}

We performed TVE between 1 January 1999 and 13 July 2001 on 78 infertile patients. Their average age was 33 (32-34) years, and the mean number of years of their infertility problem was $3.7(3-5)$ years. We recruited three groups of patients. Group A comprised 46 patients that were operated on in Milan and Bologna, in Italy. Group B contained ten patients in Ioannina, Greece, and group $\mathrm{C}$ was composed of 22 patients in Nicosia, Cyprus. All patients were selected to be at minimal risk of pelvic adhesions, and vaginal sonography verified uterus and ovaries to be normal. The first four patients of each group were examined by laparoscopy, to evaluate the potential of the technique and minimise risks for the patients.

\section{Method}

The procedure of TVE was followed as published by Gordts et al. [7]. In the operating room the patients were placed in the lithotomy position, and a drip infusion was administrated. Heavy sedation was used as anaesthesia. After the patient had undergone disinfection with aqueous chlorhexidine solution, hysteroscopy was performed. A metallic cannula was then adjusted to the cervical os for the use of chromotubation. The cervix was lifted with a tenaculum placed on the posterior lip, and, in some cases, the central part of the posterior vaginal fornix was infiltrated with $2 \mathrm{ml}$ of $1 \%$ lidocaine. The Veress needle was introduced $1.5 \mathrm{~cm}$ below the cervix and inserted into the pelvic cavity. Approximately $200 \mathrm{ml}$ of warm saline solution was introduced into the pouch of Douglas. A $3 \mathrm{~mm}$ blunt trocar was inserted by a stab incision in the posterior fornix; then, a $2.7 \mathrm{~mm}$ diameter rigid endoscope was used, with an optical angle of $30^{\circ}$, attached to a video-camera. The saline irrigation continued throughout the procedure to keep the bowel
Table 1 Transvaginal endoscopy findings. The numbers within parentheses are percentages

\begin{tabular}{lllll}
\hline Finding & Nicosia & $\begin{array}{l}\text { Milan/ } \\
\text { Bologna }\end{array}$ & Ioannina & Overall \\
\hline Normal pelvis & $11(50)$ & $16(35)$ & $3(30)$ & $30(38)$ \\
Pelvic adhesions & $3(14)$ & $12(26)$ & 0 & $15(20)$ \\
Peritubular adhesions & $4(18)$ & 0 & $2(20)$ & $6(19)$ \\
Fibria Phymosis & $2(9)$ & $6(27)$ & $3(30)$ & $11(22)$ \\
Endometriosis & $2(9)$ & $7(15)$ & $2(20)$ & $11(15)$ \\
\hline
\end{tabular}

and tubo-ovarian structures afloat. The posterior of the uterus and the tubo-ovarian structures were carefully observed, and tubal passage, using indigo-carmine, was confirmed. In some cases the infundibulum of the endosalpinx could be visualised.

\section{Results}

All 78 patients tolerated TVE very well, and no cancellations were reported. The average time of the whole procedure was $30 \mathrm{~min}$. Hospitalisation days varied, being $4 \mathrm{~h}$ for group $\mathrm{C}, 48 \mathrm{~h}$ for group A and $24 \mathrm{~h}$ for group B. No long-term postoperative complications or infections were reported. Trocar entry complications, pain and bleeding were reported in one patient in group $\mathrm{C}$ and two in group $\mathrm{B}$, which stopped after pressure. Postoperative bleeding was reported in one patient in group B, which stopped after the port entry in the vaginal vault had been sutured. One patient in group B had a bowel perforation, which was diagnosed early and treated conservatively with antibiotics.

The visualisation of the tubo-ovarian structures was reported in all cases in group A, in $7 / 10(70 \%)$ cases in group B and in 17/22 (77\%) cases in group C. The TVE findings are shown in Table 1 and differed in each department. In $30-50 \%$ of the cases normal pelvic findings were reported. The rate of pelvic endometriosis diagnosed ranged from $9 \%$ to $20 \%$, and the overall frequency of adhesions was $20 \%$.

The number of $\mathrm{CO}_{2}$ laparoscopies needed to verify the diagnosis made by TVE ranged from $7 \%$ to $10 \%$, as shown in Table 2. The overall number of patients who avoided having to have $\mathrm{CO}_{2}$ laparoscopy, by undergoing TVE, was $41 / 78(51 \%)$. The remainder of the patients, $30 / 78(38.5 \%)$ after the diagnosis was established by TVE, needed to undergo either further surgery for adhesiolysis or IVF treatment.

Table 2 Effectiveness of transvaginal endoscopy. The numbers within parentheses are percentages

\begin{tabular}{llll}
\hline Parameter & Nicosia & $\begin{array}{l}\text { Milano / } \\
\text { Bologna }\end{array}$ & Ioannina \\
\hline Number of patients & 22 & 46 & 10 \\
Laparoscopies needed to verify the TVE diagnosis & $3(14)$ & $3(7)$ & $1(10)$ \\
Patients after TVE that were saved from having to have a laparoscopy & $17(77)$ & $21(46)$ & $3(30)$ \\
Patients needing IVF or further surgery after TVE & $2(9)$ & $22(48)$ & $6(60)$ \\
\hline
\end{tabular}




\section{Discussion}

This study presents the initial application and the results of the new method of TVE in three countries. All units demonstrated similar high diagnostic potential and minimal complication rates in the TVE procedure and wide acceptability of the method by the patients. The fact that patients underwent this procedure under heavy sedation, and that the average time of inspection was half an hour, minimised hospital stay and increased acceptability by the patients for the proposed TVE procedure. The time of hospitalisation after TVE varied enormously among the three groups and was decided in advance by every department separately, depending on their protocol rather than on the real need of patients' hospitalisation. Since TVE is a new method, the safety of the method should be secured.

The observation of micro- and filmy adhesions and foci of endometriosis seen by TVE and otherwise missed by $\mathrm{CO}_{2}$ laparoscopy makes its application attractive [8]. In patients aged close to 40 years and under pressure to achieve a pregnancy as soon as possible, it seems reasonable to reassure the woman about the fertility potential prior to her undergoing any trials with ovulation induction by ruling out the $20 \%$ chance that she might have a mechanical problem. The simplicity, safety and accuracy of the results of TVE encourage the routine application of this method in infertile women [9].

Bowel injury is one of the risks encountered when the Veress needle and then the trocar are inserted into the vaginal vault [10]. Usually, the diagnosis of wrong entry is immediate, and conservative management with antibiotics is, in most cases, enough. Usually, these injuries are very rare and are avoided by the careful selection of patients and by experience.

Transvaginal endoscopy also has its limitations, as it is not possible for the gynaecologist to inspect the anterior part of the uterus, or the anterior pelvic peritoneum [4]. Nor is it possible for the abdominal cavity to be investigated in the way $\mathrm{CO}_{2}$ laparoscopy does. However, by gaining experience, the gynaecologist can clearly recognise the appendix, omentum and even adhesions below the umbilicus. It is essential to understand that selection of patients for TVE is absolutely necessary in the first cases. Also, women suspected of having pelvic adhesions and /or needing operative laparoscopy should be excluded from TVE. The learning of the TVE technique is relatively easy, especially for gynaecologists who perform traditional laparoscopy and hysteroscopy.

When TVE and hysteroscopy methods are applied as a first choice of evaluation for all infertile woman, some hesitation arises as to whether this can be performed as an office procedure, as proposed by Gordts et al. [5] and
Brosens et al. [9]. The high rate of adhesions, $20 \%$ reported in these early studies and also found by us, probably indicates the performance of TVE/hysteroscopy in the operating room, whereas operative laparoscopy can follow for patients requiring further treatment. Of course, such an option can be always discussed and settled with the patient prior to the procedure. Recent technological advances provide trocars with a working channel, and minimal surgery can be performed by TVE [11]. Further evaluation of the potential of these new instruments is necessary to exact any conclusion.

The experience of the initial steps in learning TVE in the above-mentioned units in three Mediterranean countries demonstrates that this new method of investigating female infertility is feasible, gives accurate results and is easy to learn. It is of low cost and very well accepted by the patients. The risks for perioperative complications are minimal, depending on the surgeon's experience and selection of the patients.

\section{References}

1. Campo R, Gordts S, Rombauts L, Brosens I (1999) Diagnostic accuracy of transvaginal hydrolaparoscopy in infertility. Fertil Steril 71:1157-1160

2. Gordts S, Campo R, Puttemans P, Verhoeven H, Gianaroli L, Brosens J, Brosens I (2002) Investigation of the infertile couple. Hum Reprod 17:1684-1687

3. Shushan A, Rojansky N (1999) Should hysteroscopy be a part of the basic infertility workup?. Hum Reprod 14:19231924

4. Darai E, Dessolle L, Lecuru F, Soriano D (2000) Transvaginal hydrolaparoscopy compared with laparoscopy for the evaluation of infertile women: a prospective comparative blind study. Hum Reprod 15:2379-2382

5. Gordts S, Campo R, Brosens I (2000) Office transvaginal hydrolaparoscopy for early diagnosis of pelvic endometriosis and adhesions. J Am Assoc Gynecol Laparosc 7:45-49

6. Gordts S, Campo R, Rombauts L, Brosens I (1998) Transvaginal salpingoscopy: an office procedure for infertility investigation. Fertil Steril 70:523-526

7. Gordts S, Campo R, Rombauts L, Brosens I (1998) Transvaginal hydrolaparoscopy as an outpatient procedure for infertility investigation. Hum Reprod 13:99-103

8. Brosens I, Gordts S, Campo R (2001) Transvaginal hydrolaparoscopy but not standard laparoscopy reveals subtle endometriotic adhesions of the ovary. Fertil Steril 75:10091012

9. Brosens I, Campo R, Gordts S (1999) Office hydrolaparoscopy for the diagnosis of endometriosis and tubal infertility. Curr Opin Obstet Gynecol 11:371-377

10. Gordts S, Watrelot A, Campo R, Brosens I (2001) Risk and outcome of bowel injury during transvaginal pelvic endoscopy. Fertil Steril 76:1238-1241

11. Fernandez H, Alby JD, Gervaise A, Tayrac R, Frydman R (2001) Operative transvaginal hydrolaparoscopy for treatment of polycystic ovary syndrome: a new minimally invasive surgery. Fertil Steril 75:607-611 